\title{
Envolvimento da função renal em pacientes com leishmaniose visceral (calazar)
}

\author{
Involvement of the renal function in patients with \\ visceral leishmaniasis (kala-azar)
}

\author{
Natalino Salgado Filho', Telma Márcia A.F. Ferreira² \\ e Jackson M.L. Costa²
}

\begin{abstract}
Resumo Envolvimento da função renal em pacientes com leishmaniose visceral (calazar). Apresenta-se estudo prospectivo de 11 pacientes com LV, com o intuito de verificar as repercussões clínico-laboratoriais da função renal na doença. Realizou-se análises laboratoriais das amostras de sangue e urina, colhidas logo após confirmação diagnóstica, através do encontro de leishmanias no aspirado de médula óssea. Dois (18\%) pacientes apresentaram complicações associadas a LV. Cinco (45,4\%) apresentaram hematúria macroscópica e em um caso (No.9) manifestaçốes clínicas compatíveis com síndrome nefrítica aguda. Os resultados dos exames de urina mostraram: proteinúria em 10 (90,9\%) pacientes, hematúria $7(63,6 \%)$ e leucocitúria em $6(54,5 \%)$ casos. Nove $(81,8 \%)$ pacientes apresentaram níveis elevados de microalbuminúria caracterizando lesão glomerular. A presença de tubulopatia proximal medida através da proteína ligadora de retinol, foi observada em $5(45,4 \%)$ casos. Concluiu-se que o envolvimento renal se fez presente na maioria dos pacientes, contribuindo para a gravidade da doença.
\end{abstract}

Palavras-chaves: Leishmaniose visceral americana. Envolvimento renal. Maranhão. Brasil.

Abstract Evaluation of the renal involvement of visceral leishmaniasis (kala-azar) aiming at verifying clinical and laboratorial repercussions of the renal implication on VL. Laboratory analysis was performed of blood and urine samples collected immediately after confirming diagnosis through the finding of Leishmania in bone marrow. Two (18.1\%) patient presented complications associated with kala-azar. Five patients (45.4\%) presented macroscopic hematuria and one case ( $\left.N^{\circ} 9\right)$ clinical manifestations compatible with an acute nephritis syndrome. Laboratorial data of urine exam showed: proteinuria in 10 (90.9\%) patients, hematuria in $7(63.6 \%)$ and leukocyturia in $6(54.5 \%)$ cases. Nine (81.8\%) patients presented high levels of microalbuminuria, characterizing glomerular lesion. The presence of proximal tubulopathy, measured through retinol binding protein observed in $5(45.4 \%)$ cases. Conclusion: renal involvement was manifested in most subjects, contributing to the severity of the disease.

Key-words: American visceral leishmaniasis. Renal involvement. Maranhão. Brazil.

As leishmanioses (visceral e tegumentar) apresentamse como um bom modelo para estudos da imunopatogênese e de suas manifestações clínicas, devido ao acentuado polimorfismo antigênico, desencadeando no hospedeiro reações imune do tipo celular e humoral'131621.

A leishmaniose visceral (LV) ou calazar distribui-se nos quatro continentes, com índice de letalidade próximo a $95 \%$ nos casos não tratados. No Brasil, é endêmica em 19 (70,3\%) estados, destacando-se Ceará, Bahia, Maranhão, Piauí, Rio Grande do Norte e Minas Gerais ${ }^{10}$. No Maranhão foram notificados casos em $92(42,4 \%)$ dos municípios, ocorrendo sobretudo nas áreas periurbanas das cidades, constituindo-se em importante problema de saúde pública ${ }^{14}$.

\footnotetext{
1. Departamento de Medicina I da Universidade Federal do Maranhão, São Luis, MA. 2. Núcelo de Patologia Tropical e Medicina Social do Departamento de Patologia da Universidade Federal do Maranhão, São Luís, MA.

Endereço para correspondência: Prof. Jackson M.L. Costa. Centro de Pesquisas Gonçalo Muniz/FIOCRUZ. R. Valdemar Falcão, 121 - Brotas, 41295-001

Salvador, BA.

Tel: $5571356-8782$

e-mail: npatufma@elo.com.br

Recebido para publicação em 17/9/2001.
} 
A doença caracteriza-se por febre intermitente e ou irregular $\left(38 / 39^{\circ} \mathrm{C}\right)$, hepatoesplenomegalia, anemia, evoluindo com anorexia, emagrecimento, astenia, edema, manifestações hemorrágicas. Raramente apresenta-se como uma síndrome ictérica de difícil prognóstico, a evolução é lenta, levando os pacientes à caquexia e complicações severas. Quando tratados precocemente os pacientes evoluem para cura clínica em $98 \%$ dos casos $^{14} 17$.

O envolvimento renal, intersticial e/ou glomerular é um acometimento bem conhecido das infecções produzidas pela $L$. donovani em animais experimentais ${ }^{911}$. Em humanos mais raramente, glomerulonefrites e lesões tubulointersticiais têm sido descritas, provavelmente como uma expressão de doença por imunocomplexos, ocorrendo com outras parasitoses como malária e esquistossomose. $\mathrm{Na}$ maioria dos casos apresenta uma glomerulonefrite proliferativa e nefrite intersticial e, em decorrência das lesões renais ocorrem distúrbios de sua função, podendo ser observado albuminúria e hematúria ${ }^{1319}$.

Brito e cols ${ }^{78}$, ao estudar aspectos histopatológicos do rim de 3 pacientes com LV, evidenciou, à microscópia ótica proliferação celular, espessamento fibrilar e uma leve expansão mesangial, não encontrando alterações de membrana basal. A imunoflüorescência revelou IgG

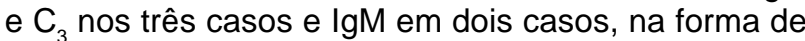
depósitos localizados principalmente em área mesangial.

A atividade policlonal de células $B$ (APB) é um achado comum em infecções crônicas, associados a produção de anticorpos e imunocomplexos potencialmente nefritogênicos ${ }^{1520}$. Galvão-Castro e cols ${ }^{15}$, sugerem APB na LV a partir do encontro de hipergamaglobulinemia às custas de $\operatorname{lgG}$ e $\operatorname{lgM}$, e a presença de anticorpos contra várias proteínas e haptenos.
Salgado Filho ${ }^{22}$, ao estudar 10 pacientes com LV na fase aguda, observou a presença de síndrome nefrítica aguda em dois pacientes, constituindo achado de grande importância, além de demonstrar uma intensa ativação policlonal de linfócitos B e hipocomplementemia em 60\% dos pacientes.

Nieto e cols ${ }^{18}$, ao estudaram 10 cães com LV, evidenciaram dano renal discreto constituído por glomerulonefrite do tipo lesão mínima. Na microscopia eletrônica, a membrana basal glomerular parecia estar normal e apenas os podócitos mostravam uma perda de pedicelos.

Nos últimos 10 anos, métodos sensíveis têm sido usados para detectar a presença de proteinúria tubular, sendo capazes de identificar a existência de disfunção do túbulo proximal. Entre esses métodos destaca-se, a proteína transportadora de retinol (RBP), considerada como responsável pelo transporte de retinol do fígado para os tecidos epiteliais. Trata-se de uma microproteína cujo peso molecular é de 21.000 daltons e que se encontra no plasma (90\%) ligada à transferrina. Após a liberação do retinol nos tecidos-alvo, ocorre perda da afinidade da ligação com a pré-albumina e essa forma livre da RBP é rapidamente eliminada do plasma por filtração glomerular, sofrendo em seguida reabsorção e catabolismo no túbulo proximal. Dessa forma, a RBP permite sua utilização como importante marcador de tubulopatia proximal ${ }^{4}$.

Em função do aumento do número de casos de LV, em nosso Estado, e da presença de manifestações clínicas sugestivas do envolvimento da função renal, pretende-se neste estudo, avaliar as alterações laboratoriais que possam expressar algum comprometimento da função renal na ausência de terapêutica específica contra a referida doença.

\section{MATERIAL E MÉTODOS}

Realizou-se um estudo prospectivo com 11 pacientes portadores de LVA forma aguda, sendo que 10 foram internados nas enfermarias de doenças infecciosas e parasitárias (DIP) e clínica pediátrica do Hospital da Universidade Federal do Maranhão (UFMA) e apenas um foi atendido a nível ambulatorial no Hospital Tarquínio Lopes Filho-HTLF. O estudo foi desenvolvido no período de agosto de 1997 a junho de 1998, sendo os dados dos pacientes catalogados em fichas protocolares constando: idade, sexo, cor, profissão, residência atual e anteriores, existência de animais doentes no domicílio e vizinhanças, história de febre recente (1 a 4 semanas), queda do estado geral, palidez cutâneo-mucosa, edema, hepatoesplenomegalia e ausência de tratamentos específicos.

Todos apresentavam diagnóstico confirmado através de punção da medula óssea com pesquisa direta de Leishmania em esfregaços corados pelo método de Giemsa. Os locais de punção variaram de acordo com a idade do paciente: terço superior e anterior da tíbia (até 2 anos de idade), crista ilíaca posterior (3 a 12 anos) e esterno (acima de 12 anos). Foram colhidas amostras de sangue (10ml) de cada paciente tão logo fosse confirmado o diagnóstico de LV. Para a determinação dos níveis de lgG, $\lg \mathrm{M}$, e IgA utlizou-se o método de imunodifusão radial, usando placas Tri-partigem do laboratório BehringAlemanha, segundo técnica de Mancini, Carbonara e Heremanno (apud: Salgado Filho ${ }^{22}$ ). Realizou-se ainda dosagem de proteínas totais e frações, albumina, globulina, proteína transportadora de retinol (RBP), uréia e creatinina.

Colheu-se ainda de cada paciente $30 \mathrm{ml}$ de urina para a realização dos exames: urina tipo 1- análise química, utilizando-se tiras reagentes (N-Multistix) para proteinúria qualitativa. No exame do sedimento urinário, centrifugou-se $10 \mathrm{ml}$ da urina por 5 minutos a 3.000rpm, em seguida 0 sobrenadante era desprezado e o sedimento examinado em microscópio óptico comum. A microalbuminúria foi analisada pela técnica de radioimunoensaio com valor de referência menor que $15 \mathrm{mcg} / \mathrm{min}$. Para análise das uroculturas, utilizouse os meios de cultura Brolacin Agar (CLED Agar) e MacConkey Agar (seletivo para gram negativo). 


\section{RESULTADOS}

A análise dos achados clínicos à época da internação, mostrou que todos os pacientes apresentaram quadro febril, anemia, hepatoesplenomegalia e adenomegalia. Em $5(45,4 \%)$ pacientes constatou-se hematúria macroscópica, $5(45,4 \%)$ ascite, 3 casos epistaxe.
Manifestações relacionadas com o envolvimento do estado geral como astenia, prostação e perda ponderal foram observados em $100 \%$ dos pacientes. Um resumo das principais características clínicas dos pacientes estudados encontra-se na Tabela 1.

Tabela 1 - Manifestações clínicas de 11 pacientes estudados, portadores de leishmaniose visceral (LV) na fase aguda.

\begin{tabular}{|c|c|c|c|c|c|c|}
\hline \multirow[b]{2}{*}{ Pacientes } & \multicolumn{6}{|c|}{ Manifestações clínicas } \\
\hline & anemia & ascite & astenia & hepatoesplenomegalia & perda ponderal & febre \\
\hline 1 & + & + & + & + & + & + \\
\hline 2 & + & - & - & + & + & + \\
\hline 3 & + & + & + & + & + & + \\
\hline 4 & + & - & - & + & + & + \\
\hline 5 & + & - & + & + & + & + \\
\hline 6 & + & - & + & + & - & + \\
\hline 7 & + & - & + & + & + & + \\
\hline 8 & + & - & + & + & + & + \\
\hline 9 & + & + & + & + & + & + \\
\hline 10 & + & + & + & + & + & + \\
\hline 11 & + & + & + & + & + & + \\
\hline
\end{tabular}

Dos 11 pacientes, $8(72,7 \%)$ eram do sexo masculino e $3(27,3 \%)$ do feminino. Em relação à cor, tivemos 3 brancos e $8(72,7 \%)$ não brancos, quanto à faixa etária, 5 pacientes estavam entre 0-10 anos, os demais entre 11-25, os extremos foram de 1 e 25 anos, com a mediana de 11 anos. O tempo de doença até a internação foi relativamente curto, em média 2,7 semanas, permitindo a realização do nosso estudo na fase inicial da doença. Todos residiam na área periurbana de São Luis-MA e seis (54,5\%) pacientes relataram a presença de cães doentes no peridomicílio.

Notou-se hiperglobulinemia e hipoalbuminemia em todos os casos, sendo que a IgG esteve elevada em $100 \%$, quando comparada a $\operatorname{lgM}(45,4 \%)$ e IgA em 4 $(36,3 \%)$ dos casos. Os níveis de uréia e creatinina séricas mantiveram-se dentro dos padrões de normalidade, com exceção de um paciente (caso 5) que apresentou discreto aumento desses valores. $\mathrm{Na}$ análise dos níveis de uréia e creatinina, levou-se em consideração os valores de referência associado a idade, sexo, massa muscular e o fato de não termos medido a filtração glomerular dos pacientes, achou-se que pelo menos $8(72,7 \%)$ tiveram creatinina elevada dentro dos referidos valores (Tabela 2).

No que diz respeito ao exame de urina tipo 1, a presença de proteinúria foi positiva em 10 pacientes. Leucocitúria presente em 6 e hematúria em 7 (63,6\%) pacientes. A urocultura foi negativa em todos os casos estudados. Ao analisarmos o grau de comprometimento tubular proximal, verificou-se que $5(45,4 \%)$ pacientes apresentaram aumento da excreção dos níveis de RBP e nove $(81,8 \%)$ apresentaram níveis elevados de microalbuminúria. Cinco pacientes apresentaram simultaneamente aumento na excreção dos níveis de RBP e microalbuminúria (Tabela 3 ).

\section{DISCUSSÃO}

O envolvimento da função renal na LV em animais experimentais é um achado conhecido e tem sido objeto de vários relatos. No entanto, estudos sobre a repercussão dos aspectos clínicos da lesão renal no ser humano ainda são escassos. A maioria dos estudos têm relatado mudanças nos achados histopatológicos, contudo são poucos os que evidenciaram a clínica e as alterações laboratoriais do dano renal antes ou após o tratamento 3591318 .

A presença de edema em membros inferiores e ascite em um dos pacientes (caso 9), apesar de serem sinais clínicos da LV, em nosso estudo levaram-nos a pensar em envolvimento renal devido a associação com outras manifestações clínicas, como hematúria, proteinúria e elevação dos níveis da pressão arterial.

À semelhança do que foi descrito por Alencar ${ }^{12}$, observou-se que a principal faixa etária acometida encontrava-se entre zero a dez anos, onde ocorreu mais de $80 \%$ dos nossos casos. Existiu uma prevalência maior no sexo masculino, e a quase totalidade dos casos ocorreu em áreas periurbanas.

Nicodemo e cols ${ }^{17}$, em estudo retrospectivo realizado com 104 pacientes portadores de LV, relataram a inexistência de dados clínicos e/ou laboratoriais que 
Tabela 2 - Resultado dos níveis de uréia e creatinina séricas ( $\mathrm{mg} / \mathrm{dl})$ e globulinas dos 11 pacientes estudados com LV na fase aguda.

\begin{tabular}{|c|c|c|c|c|c|c|c|c|}
\hline \multirow[b]{2}{*}{ Paciente } & \multirow[b]{2}{*}{ Idade (anos) } & \multicolumn{6}{|c|}{ Exames complementares } & \multirow[b]{2}{*}{$\lg M(\mathrm{mg} / \mathrm{dl})$} \\
\hline & & uréia (mg/dl) & creatinina $(\mathrm{mg} / \mathrm{dl})$ & albumina $(\mathrm{g} / \mathrm{dl})$ & globulinas(g/dl) & $\lg G(\mathrm{mg} / \mathrm{dl})$ & $\lg \mathrm{A}(\mathrm{mg} / \mathrm{dl})$ & \\
\hline 1 & 25 & 30 & 0,6 & 1,9 & 6,2 & 2.800 & 110 & 99 \\
\hline 2 & 1,11 & 38 & 0,8 & 2,1 & 6,4 & 3.176 & 196 & 126 \\
\hline 3 & 12 & 16 & 0,9 & 2,6 & 9,0 & 5.308 & 314 & 174 \\
\hline 4 & 1,5 & 40 & 1,0 & 1,7 & 5,9 & 6.106 & 342 & 170 \\
\hline 5 & 15 & 61 & 1,6 & 2,4 & 7,8 & 7.230 & 251 & 66 \\
\hline 6 & 25 & 26 & 1,2 & 2,0 & 9,6 & 3.271 & 258 & 110 \\
\hline 7 & 4 & 42 & 1,0 & 1,6 & 7,9 & 7.610 & 356 & 220 \\
\hline 8 & 17 & 33 & 1,0 & 2,1 & 5,0 & 6.800 & 310 & 92 \\
\hline 9 & 11 & 27 & 0,8 & 1,7 & 5,4 & 7.710 & 220 & 210 \\
\hline 10 & 1,3 & 21 & 0,5 & 1,4 & 6,1 & 6.380 & 201 & 178 \\
\hline 11 & 8 & 22 & 0,7 & 1,6 & 7,4 & 5.100 & 102 & 148 \\
\hline \multicolumn{9}{|l|}{ Valores de } \\
\hline Referência & - & $15-45$ & $0,5-1,4$ & $3,8-5,4$ & $2,4-2,6$ & até 1.538 & $110-300$ & $50-160$ \\
\hline
\end{tabular}

Tabela 3 - Determinação dos níveis de RBP, microalbuminúria e de urina tipo 1 dos 11 pacientes com LV estudados.

\begin{tabular}{|c|c|c|c|c|c|}
\hline \multirow[b]{2}{*}{ Pacientes } & \multicolumn{4}{|c|}{ Exames complementares } & \multirow[b]{2}{*}{ hematúria* } \\
\hline & $\begin{array}{c}\text { proteína transportadora } \\
\text { de retinol (RBP) }\end{array}$ & microalbuminúria & $\begin{array}{c}\text { proteinúria } \\
\text { (mg/dl isolado) }\end{array}$ & leucocitúria* & \\
\hline 1 & 0,40 & 43 & 30 & 8 & 2 \\
\hline 2 & 0,47 & 127 & 100 & 6 & 30 \\
\hline 3 & 0,79 & 30 & 100 & 20 & 18 \\
\hline 4 & 0,03 & 5,6 & 30 & 12 & 8 \\
\hline 5 & 0,12 & 10,1 & 30 & 38 & 7 \\
\hline 6 & 0,67 & 23 & 100 & 8 & 6 \\
\hline 7 & 0,81 & 40 & 30 & 12 & 5 \\
\hline 8 & 0,88 & 120 & 100 & 60 & 20 \\
\hline 9 & 0,03 & 75 & 100 & 8 & 16 \\
\hline 10 & 0,03 & 57 & negativo & 12 & 4 \\
\hline 11 & 0,12 & 30 & 30 & 6 & 5 \\
\hline $\begin{array}{l}\text { Valores de } \\
\text { referência }\end{array}$ & até $0,40 \mathrm{mg} / \mathrm{dl}$ & menor que $15 \mathrm{mcg} / \mathrm{min}$ & negativo & até 10 & até 5 \\
\hline
\end{tabular}

sugerissem acometimento renal. Entretanto, nos exames laboratoriais de rotina desses pacientes, demonstraram a presença de proteinúria em $6,3 \%$ dos casos. Seis casos evoluíram para o óbito com quadro de oligúria e uremia. Estes dados foram de pacientes com evolução crônica, embora sinalizem a importância da agressão renal na LV, não servem de comparação com o nosso estudo, que foi realizado em pacientes na fase aguda da doença.

Caravaca e cols ${ }^{9}$ relataram o caso de um paciente com 33 anos de idade, portador de LV em fase aguda, que apresentou comprometimento renal e icterícia, evoluindo com insuficiência renal aguda, que segundo os autores, foi causada por um dano túbulo intersticial severo. Segundo estes autores, infecções sistêmicas como a LV são causa bem conhecida de nefrite intersticial aguda, tornando-a, portanto, componente próprio da doença. Além disso, acredita-se que a lesão tubulointersticial não seja provocada por imunocomplexos, mas sim, por mecanismos imunocelulares. Fato semelhante ocorreu a um dos nossos pacientes (caso 9), pois, observou-se elevações dos níveis de aminotransferases com sorologia para hepatite $B$ negativa. Em nosso caso, a paciente teve manifestações de síndrome nefrítica com a presença importante de proteinúria e hematúria.

Verificou-se que a hipergamaglobulinemia esteve presente em todos os casos estudados por nós. Conforme Salgado Filho ${ }^{22}$, estes resultados ocorrem com freqüência na LV, e constituem elementos indicativos de uma APB. Esta ocorre espontaneamente na evolução de doenças infecciosas ou autoimunes, e foi proposta inicialmente por Green Wood, a partir da observação de hiperprodução de imunoglobulinas em duas parasitoses, malária e tripanossomíase.

O envolvimento da função renal em humanos infectados por $L$. chagasi parece ser freqüente ${ }^{12} 1320$. Observou-se que em mais da metade dos nossos casos existiu alguma anormalidade urinária como proteinúria, 
hematúria e/ou leucocitúria, assim como alterações da função renal quando analisados individualmente nos pacientes estudados, concordando com os achados encontrados por Salgado Filho ${ }^{22}$.

Na prática clínica, as alterações da função renal são geralmente detectadas pela estimativa da filtração glomerular, através da depuração da creatinina endógena, das dosagens séricas de uréia e creatinina, da análise do sedimento urinário e da quantificação da proteinúria quando a mesma se encontra em grande quantidade 152223 .

Recentemente, o estudo da disfunção glomerular foi enriquecido com a microalbuminúria ${ }^{1921}$. O seu papel está bem definido na nefropatia diabética, identificando precocemente os pacientes que desenvolverão doença renal clínica manifesta. Com relação à avaliação da função tubular, progressos foram obtidos com a utilização de métodos capazes de detectar lesões precoces do túbulo proximal, através da pesquisa de proteinúria tubular e da secreção de microproteínas urinárias. Todos esses avanços são potencialmente úteis na detecção precoce de nefropatia em estágio subclínico e, a maioria deles, ainda não foi incorporada na prática rotineira ${ }^{23}$.

A determinação tanto da microalbuminúria como da proteína ligadora de retinol nos pacientes estudados mostraram importantes alterações, sendo, portanto, úteis na demonstração do envolvimento da função renal na leishmaniose visceral em sua fase aguda, indicando disfunções renais glomerulares e tubulares mesmo em pacientes com nenhuma ou pouca expressão clínica de nefropatia ${ }^{4123}$.

\section{REFERÊNCIAS BIBLIOGRÁFICAS}

1. Alencar JE. Aspectos atuais do calazar no Ceará. Revista Brasileira de Malariologia e Doenças Tropicais 26:27-53, 1974-1976.

2. Alencar JE. Expansão do calazar no Brasil. Ceará Médico 5:86102,1983

3. Andrade ZA, labuki K. A nefropatia do calazar. Revista do Instituto de Medicina Tropical de São Paulo 14:51-54, 1972.

4. Bennet PH. "Microalbuminuria" and diabetes: a critique assessment of urinary albumin secretion and its role in screening for diabetic nephropathy. American Journal of Kidney Disease 13:29-34,1989.

5. Bernard AM. Comparison of retinol binding protein and B2microglobulin determination in urine for the early detection of tubular proteinuria. Clinical Chemistry Acta 126:1-7, 1982.

6. Bernard AM. Assessment of urinary retinol binding protein as an index of proximal tubular injury. Clinical Chemistry 33:775-779,1987.

7. Brito T, Hoshino-Shimizu S. Glomerular involvement in kala-azar. American Journal of Tropical Medicine 24:8-18,1975.

8. Brito T, Hoshino-Shimizu S, Amato Neto V, Duarte MIS, Penna DO. Glomerular involvement in human kala-azar: a light, immunofluorescent and electron microscopy study. American Journal of Tropical Medicine and Hygiene 24:9-18,1975.

9. Caravaca F, Munõz A, Pizarro JL, Santamaria JS, FernadezAlonso J. Acute renal failure in visceral leishmaniasis. American Journal of Nephrology 11:350-352,1991.

10. Costa JML, Viana GMC, Saldanha ACR, Nascimento MDSB Alvim AC, Burattini MN, Silva AR. Leishmaniose visceral no estado do Maranhão, Brasil. A evolução de uma epidemia. Cadernos de Saúde Pública. Rio de Janeiro 11:321-324,1995.

11. Councilman WT. Acute interstitial nephritis. Journal Experimental Medicine 3:393-420, 1898.

12. Dutra M, Martinelle R, Carvalho EM, Rodrigues LE, Brito E, Rocha $H$. Renal involvement in visceral leishmaniasis. American Journal Kidney Diseases 6:22-27,1985.
13. Duarte MIS, Silva MRR, Gotto H, Nicodemo EL, Amato Neto V. Interstitial nephritis in human kala-azar. Transactions of the Royal Society of Tropical Medicine and Hygiene 77:531-537,1983.

14. Fernández-Guerreiro ML, Aguado JM, Buzon L, Barros C, Montalban C, Martin T, Bouza E. Visceral leishmaniasis in immunocompromised hosts. American Journal of Tropical Medicine 83: 1098-1102,1987.

15. Galvão-Castro B, Sá Ferreira JA, Marzochi KF, Marzochi MC, Coutinho SG, Lambert PH. Polyclonal B activation, circulating immune complexes and autoimmunity in human american visceral leishmaniasis. Clinical Experimental Immunology 56:58-66,1984.

16. Ministério da Saúde. CENEPI/FUNASA. Evolução temporal das doenças de notificação compulsóris no Brasil de 1980 a 1998. Boletim epidemiológico. Edição especial. III: 48pg, 1999.

17. Nicodemo EL, Duarte MIS, Nicodemo AC, Amato Neto V. Aspectos clínico-laboratoriais da nefrite intersticial da leishamniose visceral. Revista Paulista de Medicina 102:19-22,1984.

18. Nieto CG, Navarrete J, Habela MA, Serrano F, Redondo E. Pathological changes in kidneys of dogs with natural Leishmania infection. Veterinary Parasitology 45:33-47, 1992.

19. Prasad LSN, Sen S, Ganguly SK. Renal involvement in Kalaazar. Indian Journal Medicine. Research 95:43-46,1991.

20. Pereira AB. Estudo laboratorial das proteinúrias. Jornal Brasileiro de Nefrologia 15: 7-11,1992.

21. Tanner CE. Immunobiology of visceral leishmaniasis. Clinical immunology and immunopathology 78:108, 1996.

22. Salgado Filho N. Estudo da ocorrência de imunocomplexos circulantes e ativação do sistema do complemento em pacientes com a forma aguda de leishmaniose visceral. Tese de Mestrado, Escola Paulista de Medicina, São Paulo, 1987.

23. Waller KV, Ward KM, Mahan JD, Wismatt DK. Current concepts in proteinuria. Clinical Chemistry 35:755-765,1989. 